Article

\title{
Multi Criteria Decision Analysis Technique for Solar Power Sites Selection in Duhok
}

$$
\text { Governorate - Iraq }
$$

\author{
Gaylan Rasul Faqe Ibrahim 1, 2,* Kamaran Wali Mahmood ${ }^{2}$ and Muhammad Mirza Mahmud ${ }^{2,}$ \\ 1 Geography Department, Faculty Arts, Soran University, Kurdistan Region, Iraq; gailan.faqe@soran.edu.iq \\ 2 Department of Geography, College of Humane Sciences, University of Halabja, Halabja, Iraq \\ 3 Geography Department / Collage of Arts / Salahaddin University - Erbil; kamaran.mahmood@su.edu.krd \\ 4 Student in Geography Department, Faculty Arts, Soran University, Kurdistan Region, Iraq; \\ mma447@geoa.soran.edu.iq \\ * Correspondence, gailan.faqe@soran.edu.iq; Tel.:009647504618417
}

\begin{abstract}
Fossil fuels are non-renewable sources of energy, used particularly in developing countries. There are insufficient fossil fuels and their availability is gradually declining. This leads to a steady increase in prices. Renewable energy is clean, cost-effective and limitless. The considerable population growth and industrial growth have made the construction of solar power plants essential in developing countries. The study used Boolean logical-AHP techniques to select a suitable site for solar power in Duhok Governorate. The result indicated that $68.5 \%$ of the area in the governorate of Duhok is available for solar power station construction, especially the most appropriate zone which has $132.2 \mathrm{sq}$. $\mathrm{km}$ and can provide more than 8000 megawatts of solar energy. Most of the appropriate areas are in the south and southwest regions of the governorate, located mostly in the districts of Bardarash, Shekhan and Semel, situated between the major cities of Mosul, Erbil and Duhok. These locations can supply a significant amount of clean, renewable energy for these areas.
\end{abstract}

Duhok, Governorate, Solar Power, MCDA, AHP, Boolean

Keywords: Duhok Governorate; Solar Power; MCDA; AHP; Boolean

\section{Introduction}

The world's population continues to grow, urban areas are projected to increase by $50 \%$ in the future, and, in turn, increase the need to meet the needs of pre-emptive strike activities (What are examples of "pre-emptive strike activities" of the UN?) (United Nations Department of Economic and Social Affairs 2018). Increasing population growth and the industrialization of countries around the world increase the use of energy resources [1]. Evidence indicates that the energy demand of the world for non-renewable energy sources has increased substantially in recent years, and the need for renewable energy, especially wind and solar, has received much attention from most countries [2]. The global use, non-renewable fossil fuel has had a detrimental effect on the environment [3], ). Environmental degradation and climate change, which are global problems, are the result of fossil fuel consumption. Also, the substantial use of non-renewable fossil fuels has increased the importance of finding and using renewable sources of energy [4], [5].

The importance of renewable energy is increasing day by day, but at the same time fossil fuel needs time to be produced naturally. With reduced reserves, fossil fuel prices rise because they are non-renewable, making renewable energy a good alternative to fossil fuel [6]. Solar energy is the best example of renewable energy because solar energy can be used to generate energy without $\mathrm{CO} 2$ Beaded air emissions [7]. Use of renewable energy not only preserves the environment, it also 
prolongs the life of fossil fuel resources, making it possible for governments to create a dedicated infrastructure for renewable energy use[4].

Production of electricity through fossil fuels harms the environment; on the other hand, there are many problems even with a small amount of electricity. It should be noted that in order to reap the benefits of renewable fuels, it is necessary to plan good facilities and continuous support [8]. Solar energy is one of the renewable energies that has inexhaustible resources. The direct harvesting of energy from sunlight utilizing photovoltaic (PV) tools is increasingly documented as an integral component of future global energy supply. The reduced supply of fossil fuels and the realization of the adverse effect of emissions of $\mathrm{CO} 2$ and other greenhouse gases in the atmosphere drive research and deployment of clean energy sources, particularly renewable energy [9]. One source of energy, which has rapidly increased its production ratio in the world, is solar energy. European governments are expected to increase production by $20 \%$ in 2020 , according to plans to produce solar energy. Solar energy production in the United States increased by $80 \%$ in 2012 compared to other years. The Chinese government was also successful in increasing electricity generation from $2 \mathrm{GW}$ to $35 \mathrm{GW}$ by solar radiation between 2011 and 2015. The governments of Germany, Italy, Japan, Spain and U.S planned to increase the production of solar power plants in 2011[10], [11].

Iraq is one of the Middle Eastern governments that has little electricity and, every year, there are problems in production and sharing. The Kurdistan Region of Iraq is also subject to the same problems. Because it was only able to generate electricity for 12 hours a day in 2017, the Iraqi government has paid increased attention to renewable energy, but has failed to produce results due to political turmoil and an unsustainable economy [12]. Unfortunately, the Iraqi Kurdistan Region derives much of its electricity needs from fossil fuels, accounting for $85 \%$ of all electricity generated, while the other $15 \%$ is generated by two hydroelectric stations. Unfortunately, less than $1 \%$ is obtained through solar power plants [13]. The Kurdistan Region is geographically located in a sunny region, which means that it has no problem with the supply of solar radiation [14].

Land management, and its optimal use, is another important issue that is considered by governments and experts today due to the importance of natural resources and their proper use. Determining the proper location for photovoltaic solar construction requires careful consideration of technical, ecological and economic criteria, most of which are of local importance [15]. The most important issues in the use of solar energy is the location of its use, which has a major impact on the efficiency of solar power generation equipment and devices [16], [17]. Geographical Information Systems (GIS) has become exceedingly widespread for varies studies of site selection, particularly for energy design [18]. In recent years, GIS and Multi-Criteria Decision Making (MCDM) are prevailing techniques available to the decision-makers and site selection subjects [19]. Since their emergence, the GIS and Multi-Criteria Evaluation (MCE) methods have been increasingly used as a significant spatial decision-making tool for assessing appropriate sites [3].

Analytic Hierarchy Process (AHP), a widely used MCDA system, solves

complicated issues with multiple criteria in a hierarchical structure. The AHP technique employs linear algebra in the formulation of hierarchical constructions, matrices and measures of steps [20], and it is usually used in different fields, such as energy, environment [21]. Moreover, other studies ((Akkaş.Pdf, 2017.; Al Garni \& Awasthi, 2017b; Asakereh et al., 2014; Charabi \& Gastli, 2011; Ding et al., 2018; Effat, 2013; Janke, 2010; Van De Kaa et al., 2014) used GIS, combined with AHP-MCE techniques, to identify an optimal site selection for solar power plants. The recent study aims to identify suitable sites for solar power plants by employing GIS-based Boolean logical analysis. 


\section{Materials and Methods}

\subsection{Case Study}

The case study location is Duhok Province, located in the northern part of Iraq and the Kurdistan region (Figure.1), between the latitudes from $36^{\circ} 12^{\prime} 32.77^{\prime \prime}$ north to $37^{\circ} 22^{\prime} 49.1^{\prime \prime}$ north, and between the longitudes from $42^{\circ} 21^{\prime} 0.22^{\prime \prime}$ east to $44^{\circ} 18^{\prime} 13.31^{\prime \prime}$ east. It covers an area of 10,730.4 square kilometers. According to the estimations of Kurdistan Region Statistics Office (2020), the population of the case study reached 1,595,945 people in 2019. The terrain ranges between $172-2577$ meters above sea level and is divided into two basic units, mountainous, and semi-mountainous territory.

The climate is similar to the Mediterranean region, which is characterized by a dry, hot in summer, with lower temperatures and higher humidity in winter, and two short seasons of spring and autumn [29]. Administratively, the province consists of seven districts: Center, Semel, Zakho, Amedi, Akre, Bardarash, and Shekhan.

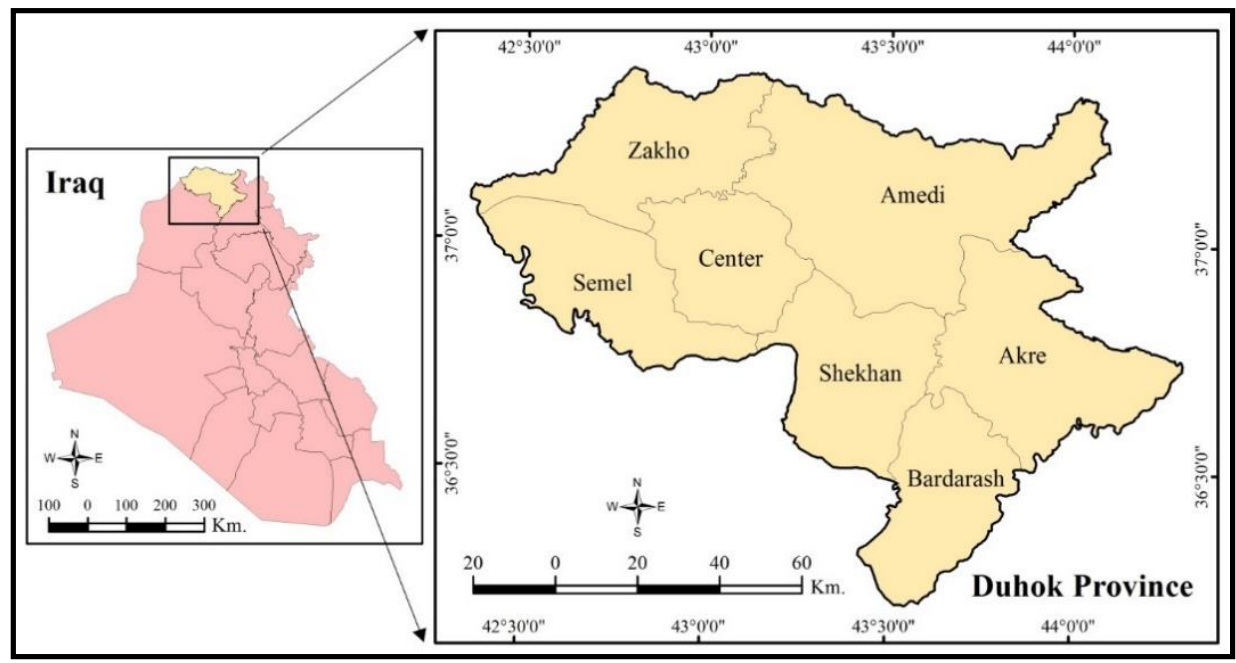

Figure 1: Location map of Duhok Province

\subsection{Generation of Boolean Map}

This process is one of the most important steps in removing some constraints from the suitability model, utilizing the Boolean logic on the data illustrated in Table-1. The Boolean logic model is the most basic way to combine GIS layers. In this method, the combination of layers is based on the zeroone rule and the final output is the map, divided into two classes, which are completely suitable and unsuitable [30]. The "AND" operator is used to combine all layers to make the final potential sites in preparation of a Boolean suitability map [31]. The suitability at the kth pixel of the final map can be located in the following equation [30]:

$$
S^{K}=\sum W_{i} \times X_{i}^{K}
$$

Where $X_{i}^{K}$ is the value of criterion in the kth pixel and $W_{i}$ is the criterion weight in that pixel which is presented by 1 or 0 , therefore, if criterion is defined as unsuitable for kth pixel, then $W_{i}$ will be 0 and pixel $\mathrm{k}$ will be deleted. 


\begin{tabular}{|c|c|c|c|c|c|}
\hline Criteria & Buffer (meter) & Ranking & Criteria & $\begin{array}{l}\text { Buffer } \\
\text { (meter) }\end{array}$ & Ranking \\
\hline Sunshine & $<7.5$ & 1 & Transmission & $\leq 5000$ & 5 \\
\hline \multirow[t]{4}{*}{ (kWh/m2 /day) } & $7.5-8.0$ & 2 & line & $5001-10000$ & 4 \\
\hline & $8.1-8.20$ & 3 & & $10001-25000$ & 3 \\
\hline & $8.21-8.3$ & 4 & & $25001-40000$ & 2 \\
\hline & $>8.3$ & 5 & & $>40000$ & 1 \\
\hline \multirow[t]{6}{*}{ Slope (\%) } & $\leq 5.0$ & 5 & Road & $\leq 150$ & Restricted \\
\hline & $5.1-8.0$ & 4 & & $151-300$ & 5 \\
\hline & $8.1-15.0$ & 3 & & $301-600$ & 4 \\
\hline & $15.1-30$ & 2 & & $601-1000$ & 3 \\
\hline & $>30$ & 1 & & $1001-2000$ & 2 \\
\hline & & & & $>2000$ & 1 \\
\hline \multirow[t]{6}{*}{ Fault } & $\leq 500$ & Restricted & Pipeline & $\leq 1000$ & Restricted \\
\hline & $501-600$ & 1 & & $1001-1250$ & 1 \\
\hline & $600-800$ & 2 & & $1251-1500$ & 2 \\
\hline & $801-1000$ & 3 & & $1501-2000$ & 3 \\
\hline & $1001-1200$ & 4 & & $2001-4000$ & 4 \\
\hline & $>1200$ & 5 & & $>4000$ & 5 \\
\hline \multirow{6}{*}{$\begin{array}{c}\text { Dense } \\
\text { population }\end{array}$} & $\leq 500$ & Restricted & Land cover / use & Settlement & Restricted \\
\hline & $501-1000$ & 1 & & Agriculture & 1 \\
\hline & $1001-2000$ & 2 & & Vegetation & 2 \\
\hline & $2001-3000$ & 3 & & Bare soil & 5 \\
\hline & $3001-4000$ & 4 & & & \\
\hline & $>4000$ & 5 & & & \\
\hline \multirow[t]{6}{*}{ Village } & $\leq 200$ & Restricted & Water resources & 500 & Restricted \\
\hline & $201-400$ & 1 & & & \\
\hline & $400-600$ & 2 & & & \\
\hline & $601-800$ & 3 & & & \\
\hline & $801-1000$ & 4 & & & \\
\hline & $>1000$ & 5 & & & \\
\hline
\end{tabular}

Table 1: Criteria used in the solar power site selection suitability model

\subsection{Analytical Hierarchy Process (AHP)}

The AHP technique, first suggested by Saaty, is another process used to fix the issue of identifying weights of the criteria. It is a Multi-Criteria Decision Making (MCDM) mathematical method that merges qualitative and quantitative variables. The basic concept is the evaluation of complex problems as a wide system. AHP is now commonly used in the study of socio-economic systems due to the systematic, flexible, and practical features of it. GIS spatial analysis has been vastly applied in several fields, including site identification and assessment. The pairwise comparison is the basic calculation used in the Analytical Hierarchy Process. In addition, the priority of each criterion is specified with the basis for relatively acquired weights and then overlaid upon digital layers exposed in Table-2 [1], [5], [32], [33]. Figure-2 clarifies the framework of the entire process of selecting the best locations of solar power plants in Duhok Province. It contains four stages which are: Data collection, criteria selection, data processing, and final suitability model. 


\begin{tabular}{cc} 
Importance intensity & Definition \\
$\mathbf{1}$ & Equally Importance \\
$\mathbf{3}$ & Moderate Importance \\
$\mathbf{5}$ & Strongly more Importance \\
7 & Very strong more Importance \\
$\mathbf{9}$ & Extremely Importance \\
$\mathbf{2 , 4 , 6 , 8}$ & Intermediate values \\
\hline
\end{tabular}

Table 2: Saaty Scale

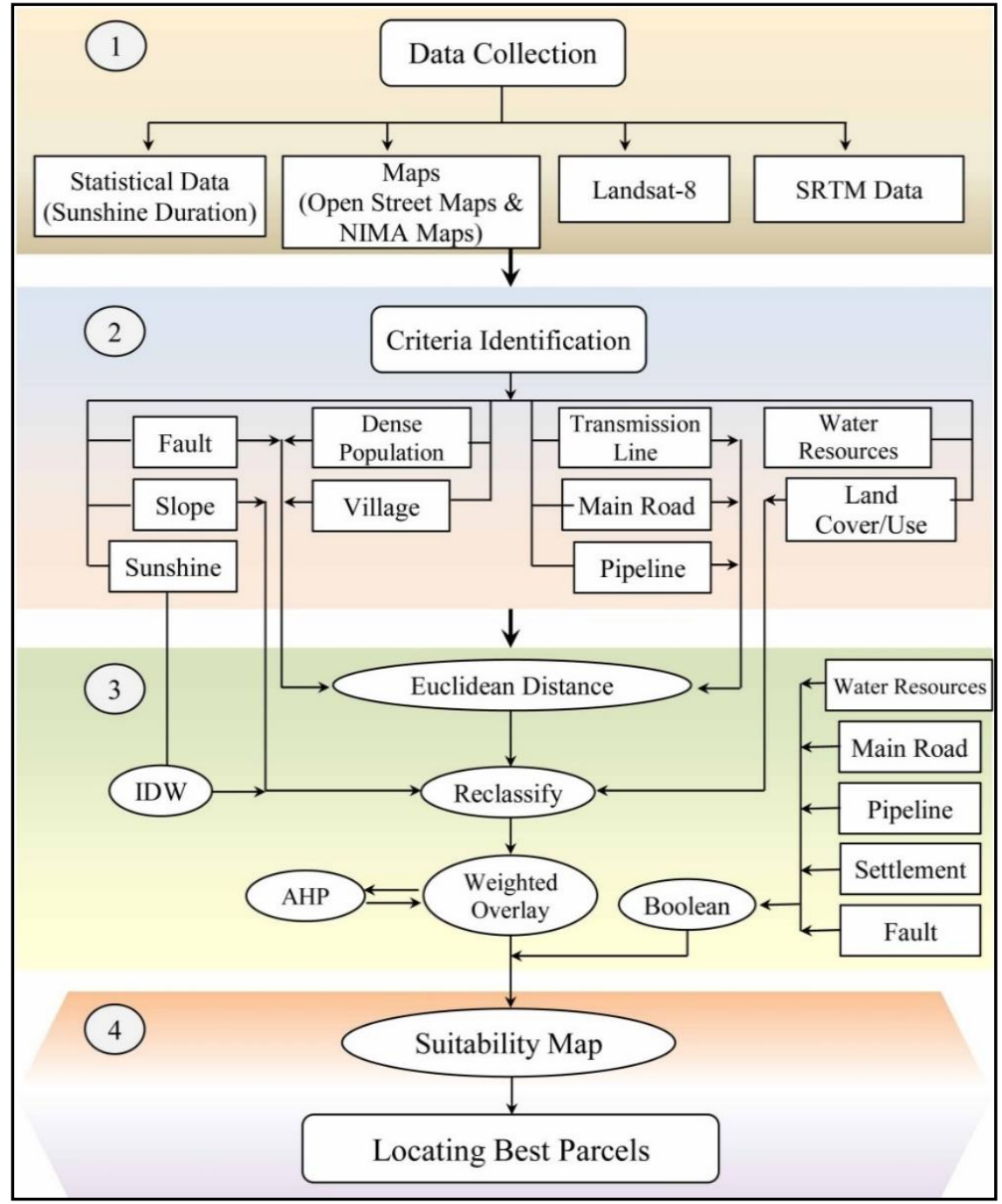

Figure 2: Conceptual Framework of the Research

\subsection{Criteria of Appropriate Solar Sites Selection}

The model of the power plant is a complicated process.[5] pointed to several important conditions in such processes, such as the site should have high solar radiation, long annual sunshine duration, the site's surface should be flat and unconstrained, with a slope facing south and should have low land-value and be readily available for building infrastructure. Also, the transmitted power costs and the environmental effects should be minimal. The study depended on a lot of criteria, which 
is shown in the Table-1 and (Figure.3), such as sunshine, slope, fault, settlement areas, transmission line, road, pipeline, land cover/use and water resources.

\subsubsection{Sunshine}

Sunshine duration, or sunshine hours, is a climatological index. It can be defined as the sum of solar radiation for a specific site in a given timeframe (a day or a year, ordinarily), and is shown as an average over several years [33]. Sunshine is one of the most important climate criteria in solar site selection; a site must have enough solar radiation for the power plant. The study gave great attention to this criterion. In general, the study area has long periods of sunshine in average; it is between 7.2 - 8.5 hour/day (General Directorate of Meteorology \& Seismology, 2019). By using the IDW interpolation method, the research created a raster map of sunshine duration distribution, the higher duration of the sunshine the higher values of suitability.

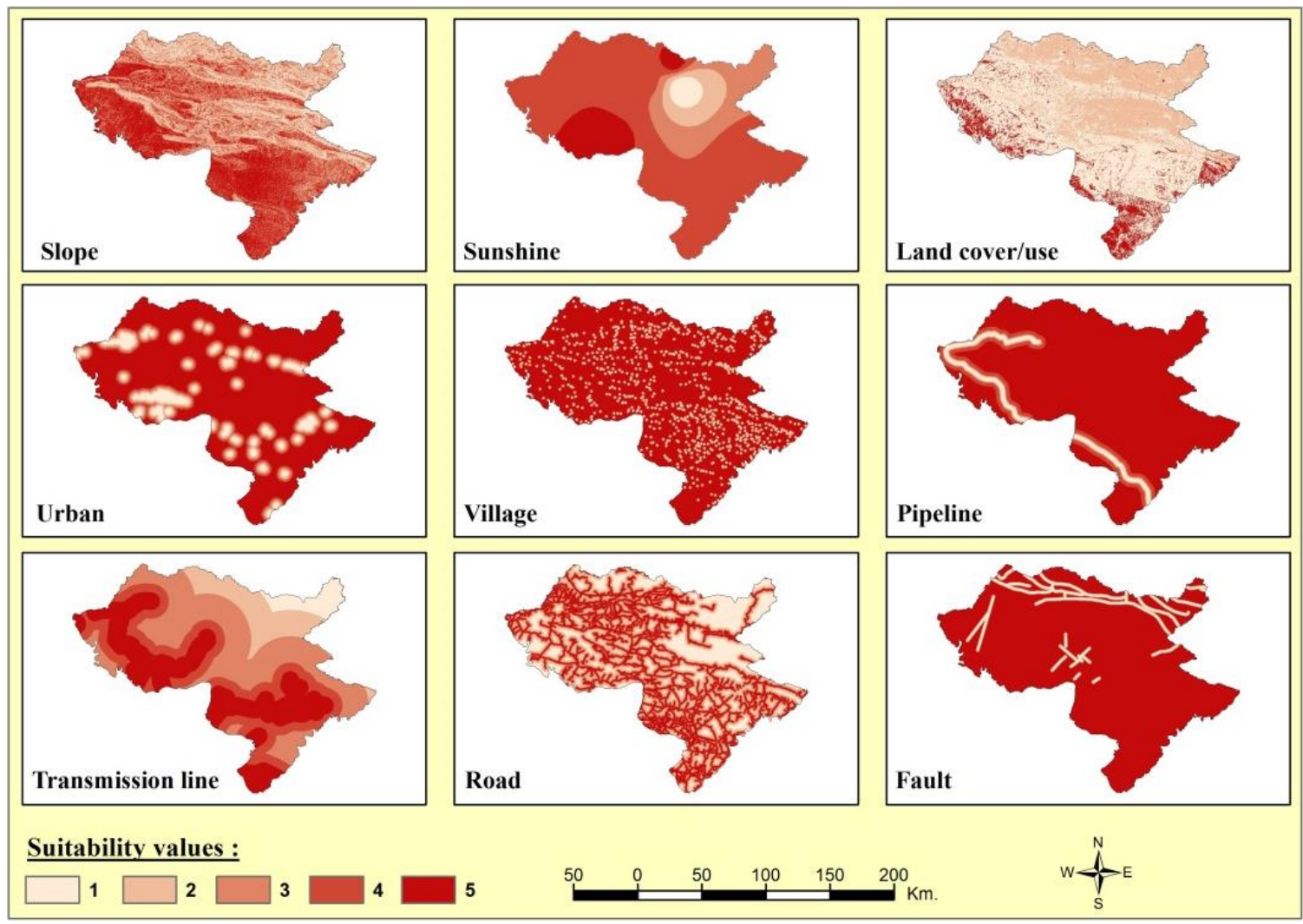

Figure 3: Reclassified Euclidean Distance Maps

\subsubsection{Slope}

The basic criterion in determining the suitability of a land tract for a solar power plant is the relief, particularly the slope [34]. As mentioned before, the solar power plant needs to be flat and located on low-land value. So the areas with slopes less than $5 \%$ got the highest score of the suitability.

\subsubsection{Proximity to Faults}

The research excluded land within a 500 meters buffer zone around faults from the solar power plant suitability model, due to construction risks. Sites with more distance from the faults were given a higher suitability value. 


\subsubsection{Proximity to Settlements}

There are urban centers and collective towns and villages in Duhok Province. The collective towns are areas where the government has forced rural citizens to move there since the 1980s. Thus, the research tried to exclude the buffer ring around these populated places for about 500 meters, while excluding 200 meters around the villages. But on the other hand, an economic consideration for the solar power plant is the proximity of a site to a populated place [27], So, the study calculated the suitability classes for 4 kilometers only, after this distance, all the places would be suitable for the solar power plants.

\subsubsection{Proximity to Transmission lines}

Another economic factor that should be taken into consideration is the proximity of the photovoltaic power plant to a transmission line The construction of new power lines to link with the photovoltaic power plant may be a highly expensive and complex process [34]. So, the research accounted for the proximity of 5 kilometers buffer to the transmission power lines, as the most suitable areas for construction of photovoltaic power plants.

\subsubsection{Proximity to Main Roads}

Accessibility is linked to the cost of conveying equipment to the location of the photovoltaic power plant and reduces the cost and complexity of long-term maintenance [34]. ). Therefore, the study preferred to keep the solar power plants near the main roads, outside the restricted zone, which is 150 meters away from the main roads.

\subsubsection{Proximity to Pipelines}

A buffer of 1 kilometer is considered as the restricted zone around the pipelines; the research tried to exclude it as much as possible since the oil pipelines are typically dangerous if they are close to any kind of power generation.

\subsubsection{Land Cover/Use}

Supervised classification of the Landsat- 8 satellite image is conducted to create the land cover/use map, which is illustrated in (Figure.4). The map shows fewer suitability values for agricultural land, and more specifically vegetation and settlement, bare soil considered to be the most suitable plots for the building of a solar farm.

\subsubsection{Water resources}

Rivers and water projects are the water resources of Duhok Province, on which the study relied. This criterion played a major role in defining the area of the restricted zone and thus decreasing the opportunity for parcels available in the suitability map. The criterion was not involved in the Euclidean distance reclassification process, as the solar power plant does not have a significant environmental effect, especially on water resources. 


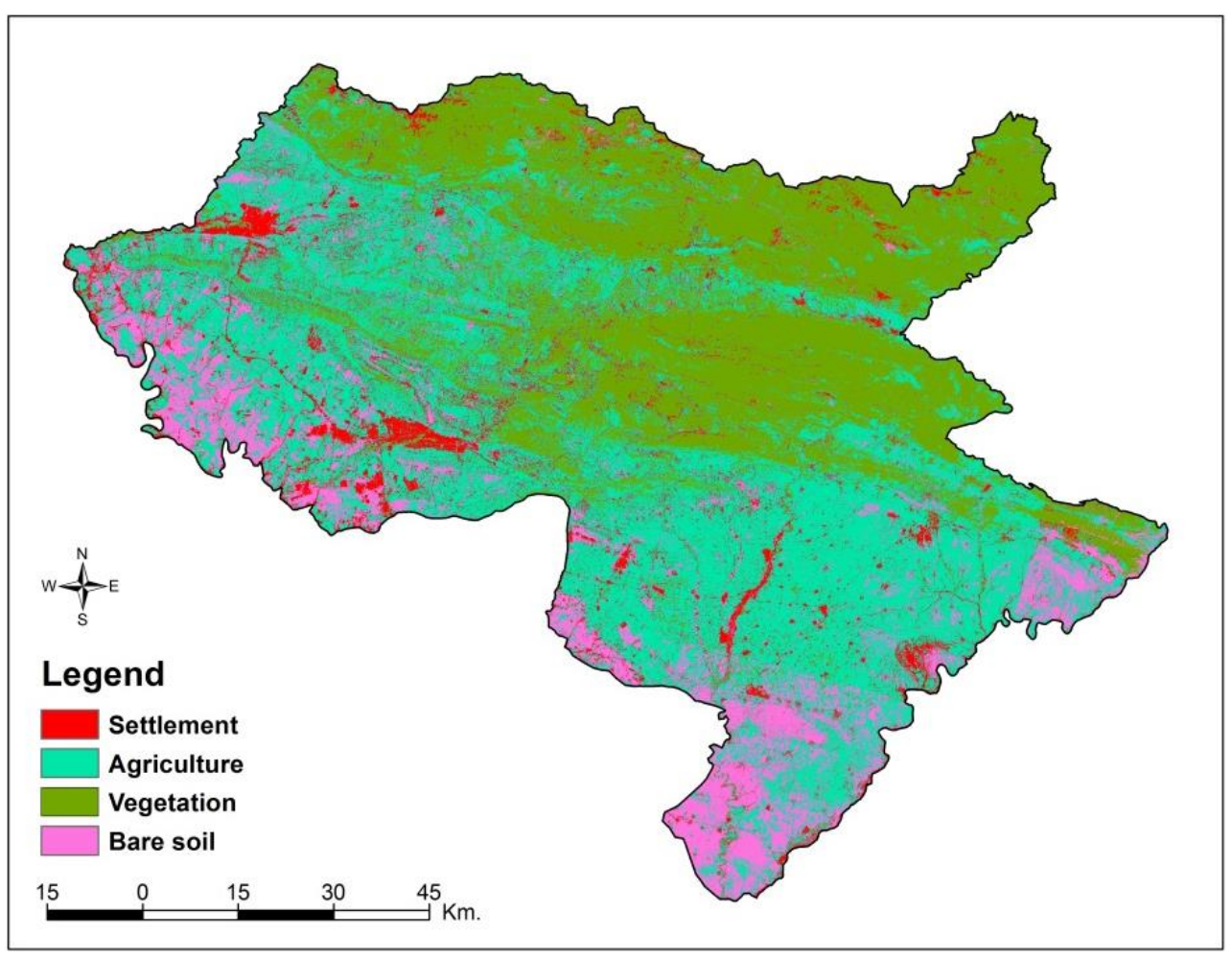

Figure 4: Land Cover/Use Result of Supervised Classification of Landsat-8

\section{Results and Discussion}

In this study, after determining the effective factors in placing the solar power farms and their role, the relevant information layers are prepared, and the required analyses are performed. Deciding on a suitable location for the construction of a power plant requires the simultaneous consideration of the factors that GIS makes possible in integrating the information layers related to these factors coherently. The selected locations are completely affected by the parameters involved in the analysis and the corresponding weights. This paper helps the reader to know how the investigation into the suitability of solar power construction sites was conducted, namely, understanding restricted areas in the Duhok Governorate, such as urban areas, rural areas, roads, rivers, transmission lines, faults, slope, land cover / use and sunshine duration.

These layers combine together with scale $(0)$, which is unsuitable for establishing this project, while scale (1) is applicable for launching this project. In many similar studies, the same value is calculated. In the case of this paper the area of the Duhok Governorate is mostly unsuitable, especially in the northwestern and southwestern parts of the study area, which contain large cities such as Duhok and Zakho. These urban areas also contain a dense road network. Meanwhile, the suitable areas for solar power plants are widely distributed, particularly of the eastern and central areas of the governorate (Figure.5).

The entire Duhok province encompasses an area of 10,730.4 sq km, of which, $68.5 \%$, or 7,349.1 $\mathrm{sq} \mathrm{km}$, is suitable for the establishment of solar farms. The remaining area, $31.5 \%$, or $3,381.3 \mathrm{sq} \mathrm{km}$, has been deemed unsuitable for the establishment of solar power plants (Table 3).

The findings of this study show the benefit of GIS in modeling and assisting environmental planning, as well as combining quantitative and qualitative criteria with different scales. Given the capabilities these systems have in spatial modeling of data, it becomes possible to generalize information, build 
new models, and test different methods. The AHP hierarchical analysis process in the GIS environment has a high priority compared to the research conducted in the field of locating power plants, in addition to considering qualitative and quantitative goals. In this method, the data is then divided into five classes (restricted, low suitability, moderately suitable and highly suitable).

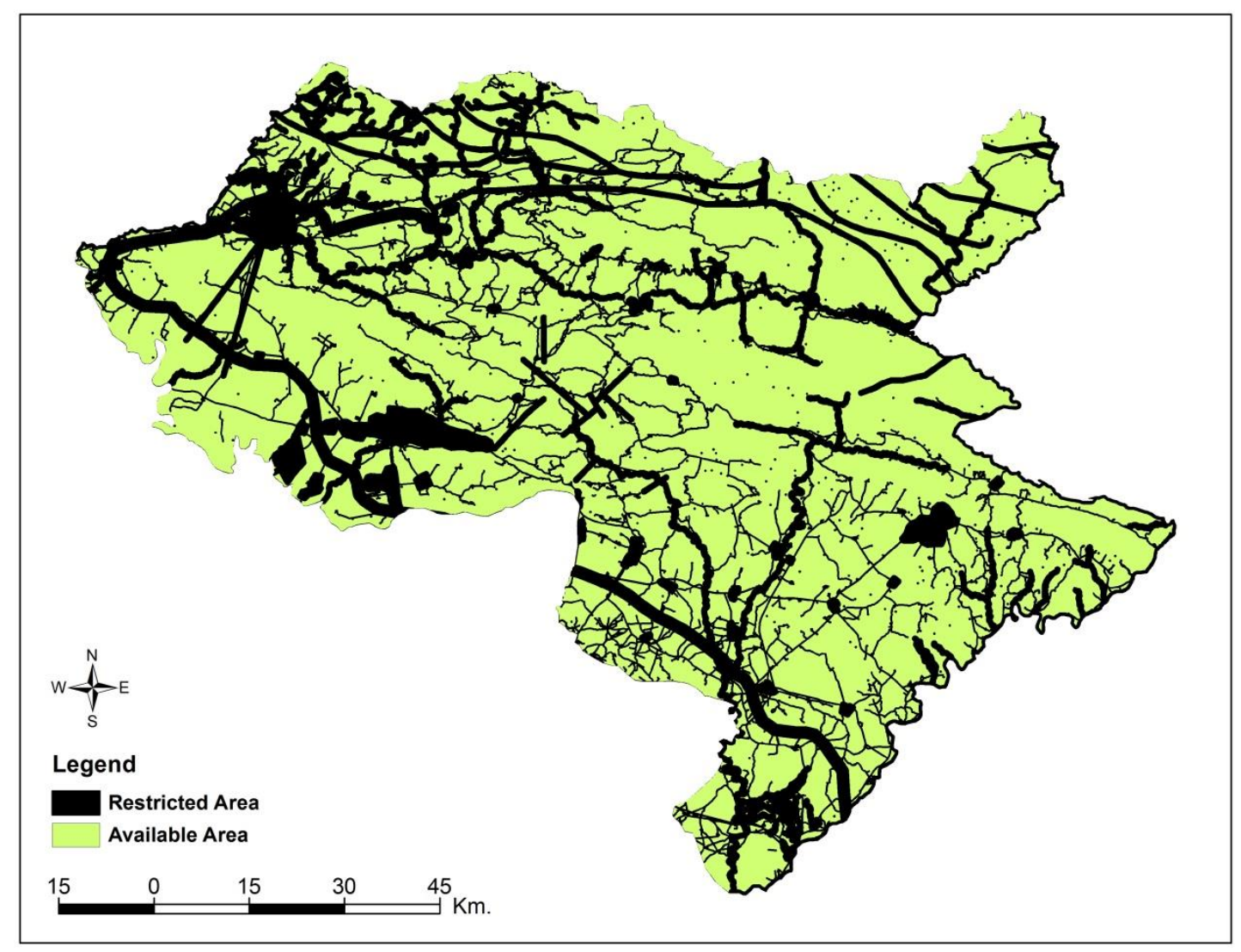

Figure 5: Restricted and Available Areas Map

\begin{tabular}{cccc}
\hline Type & Value & Area (sq.km) & \% \\
\hline Restricted & 0 & 3381.3 & 31.5 \\
Available & 1 & 7349.1 & 68.5 \\
Entire Duhok & 0,1 & 10730.4 & 100.0
\end{tabular}

Table 3: The area and its percentages of the restricted and available zones

The findings of this study show the ability of GIS in modeling and assisting environmental planning as well as combining quantitative and qualitative criteria with different scales. Given the capabilities that these systems have in spatial modeling of data, compared to research, they have the ability to generalize information, build new models, and test different methods. The Hierarchical Analysis Process in the GIS environment has a high priority compared to the research conducted in the field of locating power plants, which is in addition to considering qualitative and quantitative goals. In this method, the data is divided into four classes (restricted, low suitable, moderately suitable, and highly suitable).

Figure- 6 shows the spatial distribution of the suitability model for the solar power station, and Table 4 clarifies the allocation between the suitability classes. Low Suitable areas show an area of $3,187.9 \mathrm{sq} \mathrm{km}$ with a ratio of $29.7 \%$. Low Suitable places include Amedi and north of Akre, along with a complete irregularity in the areas of Center, Semel, Shekhan, due to the steep slope in these areas, 
especially in Amedi. The Moderately Suitable area is large and is located to the south of Akre, east of Bardarash, in northwest of the study area. This area is $4028.8 \mathrm{sq} . \mathrm{km}$ with a ratio of $37.6 \%$. It should be noted that, compared to the northern regions, these areas are less sloping. This paper focuses on the Highly Suitable areas for establishing the project. They are located in the south and southwestern territories in Bardarash, Shekhan, and Semel with an area of just 132.2 sq.km (1.2\%).

According to the results of this study, among the various criteria examined, economic criteria and energy security were of the utmost importance from the perspective of experts. Sub-criteria were the cost per kilowatt-hour, the security of the power plant's input source, the initial investment, the impact on conservation and saving of end-to-end resources, which is why expanding renewable energy resources today is essential and unavoidable.

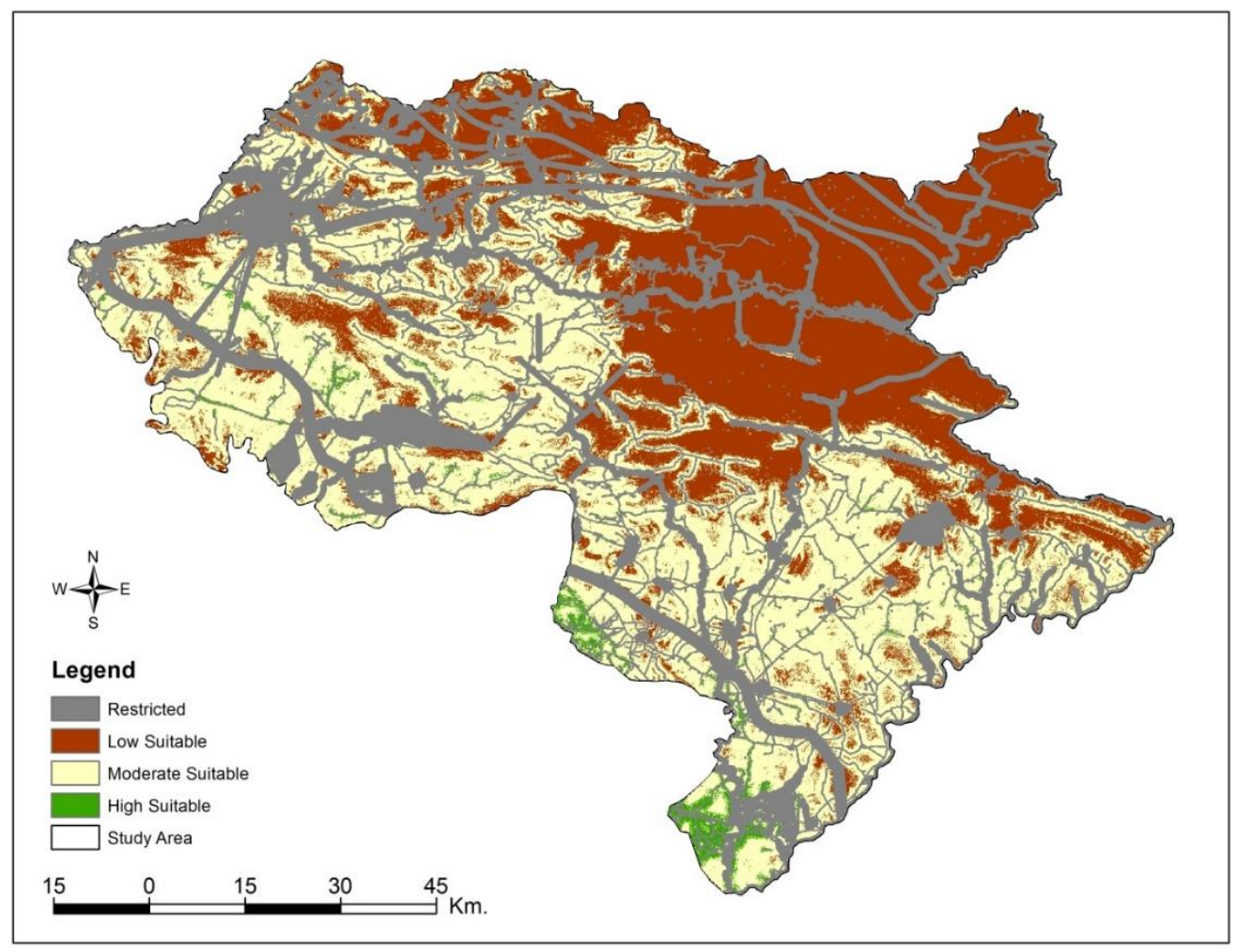

Figure 6: Solar power plants suitability model

\begin{tabular}{cccc}
\hline Suitability class & Pixel count & Area (sq.km) & \% \\
\hline Restricted & 417,448 & $3,381.3$ & 31.5 \\
Low Suitable & $68,757,246$ & $3,187.9$ & 29.7 \\
Moderately suitable & 497,381 & $4,028.8$ & 37.5 \\
Highly Suitable & 16,320 & 132.2 & 1.2 \\
Entire Duhok & $69,688,395$ & $10,730.2$ & 100.0 \\
\hline
\end{tabular}

Table 4: Suitability classes for solar power plants

Solar power is one of the world's cleanest, most renewable, available, and sustainable sources of electricity, and is less polluting in its use. A number of surface and technological issues must be considered to use this pure resource. Choosing the right location to install and use these technologies must be taken into consideration early in the project. The result is, therefore, that there is a highly 
appropriate area in the south of the province for installing solar power stations. These regions include Bardarash, Shekhan, Semel, Akre, Center, Zakho, and Amedi districts. The minimum Amedi region of $0.2 \mathrm{sq} \mathrm{km}$ with a percentage of $0.1 \%$ is shown in Table-5. Zakho, Center, and Akre have small suitable areas of construction of a solar power plant with $1.1 \%, 3.6 \%$, and $6.7 \%(1.4 \mathrm{sq} . \mathrm{km}, 4.7 \mathrm{sq} . \mathrm{km}$, and 8.8 sq. km). Semel and Shekhan have similar results of 27.5 sq. $\mathrm{km}$ and $20.8 \%$ ration. Bardarash district, with 62.1 sq. $\mathrm{km}$ and a $46.9 \%$ ratio, has the largest suitable area in Duhok province.

Given that large solar photovoltaic farms on the ground need space for other accessories, the total land needed for a one-MW solar photovoltaic power station would amount to approximately 16,187.4 sq. meters [35]. Thus, the area studied can produce more than 8,190 megawatts. Only Bardarash can produce about 3,850 megawatts. Shekhan and Semel can each produce 1705 megawatts, Akre, Center, Zakho, and Amedi can produce about 545.6 megawatts, 293.8 megawatts, 86.8 megawatts, and 12.4 megawatts, respectively. Concerning geographical characteristics, Highly Suitable areas are less sloping, with more bare soil. These landscapes also get more sunshine and are far from land cover such as forests, agricultural lands, pipelines and densely populated areas, which means that they can be the best option to help the government provide enough energy because there are few or no activities in those areas. In addition, a large portion of these Highly Suitable areas, about $95 \%$, are located in the semi-mountainous region, whereas the small remaining percentage is located in the mountainous territory.

\begin{tabular}{cccc}
\hline District & Area sq.km & \% & Megawatt \\
\hline Amedi & 0.2 & 0.1 & 12.4 \\
Zakho & 1.4 & 1.1 & 86.8 \\
Center & 4.74 & 3.6 & 293.8 \\
Akre & 8.8 & 6.7 & 545.6 \\
Semel & 27.5 & 20.8 & 1705 \\
Shekhan & 27.5 & 20.8 & 1705 \\
Bardarash & 62.1 & 46.9 & $3,850.2$ \\
Duhok Province & 132.2 & 100.0 & $8,198.8$ \\
\hline
\end{tabular}

Table 5: Suitable parcels and power production per district

The largest area of suitable solar power plant sites is situated among the big cities either in Iraq or in the Kurdistan region, such as Mosul, Erbil, and Duhok (Figure-7). This significantly helps to provide clean and renewable energy to these urban centers, in addition to the study's contribution to future work in the entire area. 


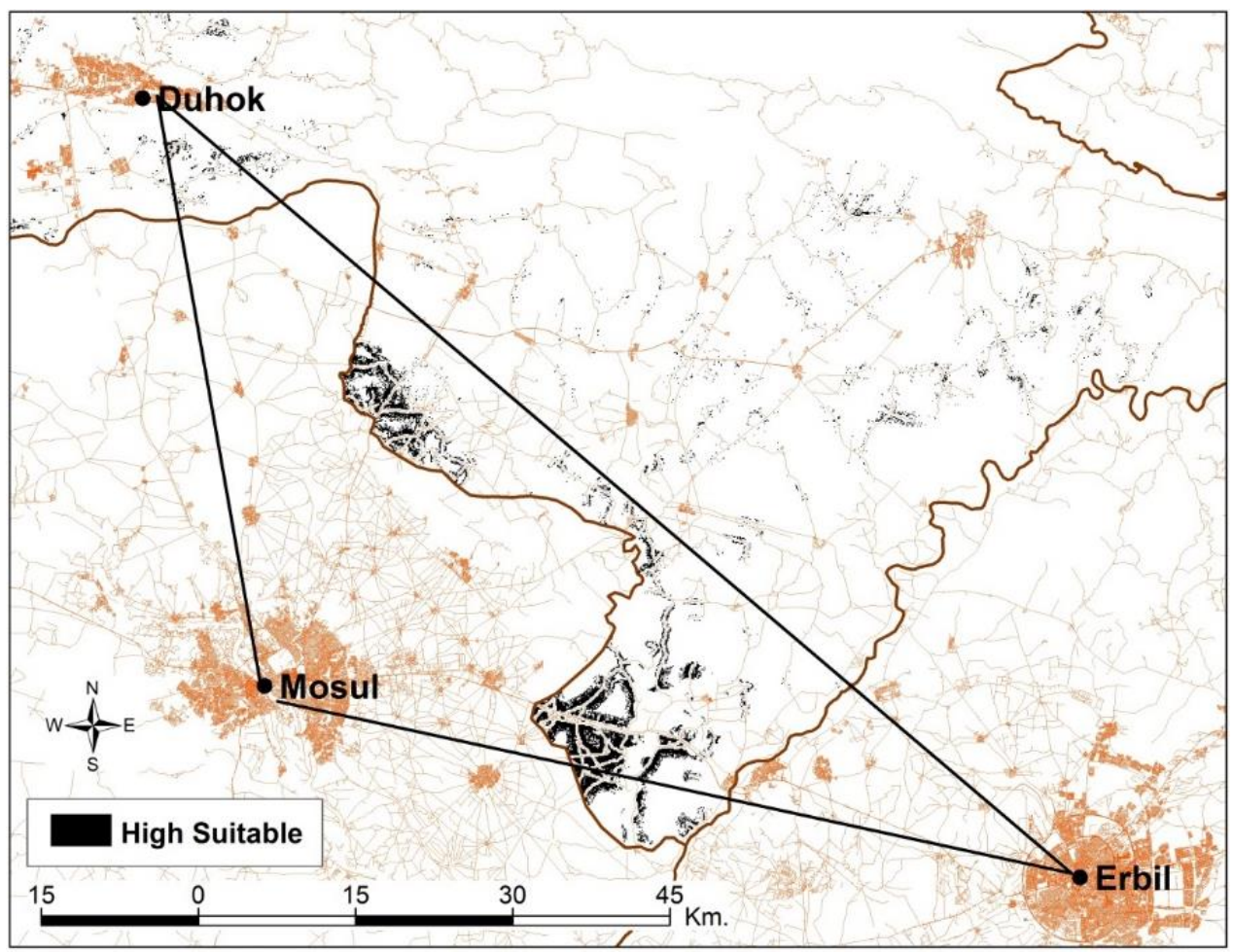

Figure 7: Location features for high suitable solar power plant

\section{Conclusion:}

This study employed the Multi-Criteria Decision Analysis to select the optimum sites for solar power plants in the Duhok Governorate, through the use of mathematical methods such as Boolean logic and Analytical Hierarchy Process (AHP), inside the environment of Geographical Information Systems. The study depended upon several criteria, related to the environmental and economic aspects, such as water resources, sunshine, slope, faults, roads, transmission lines, pipelines, settlements, and land cover/use.

There are a variety of findings in this paper, the most important of which is that 7,349.1 sq km cover the area available for solar farm construction, which occupies $68.5 \%$ of the Duhok Governorate. This available area was divided into three grades of suitability: low-suitability, moderately suitable, and highly suitable. The most suitable area is $132.2 \mathrm{sq} \mathrm{km}$ and comprises $1.2 \%$ of the governorate; this area can produce more than 8,190 megawatts of solar energy. $88.5 \%$ of highly suitable area is located in Bardarash (62.1 sq km), Shekhan (27.5 sq km), and Semel (27.5 sq km) in southern and southwestern area of the governorate. These suitable places for solar power plants have several significant characteristics including less sloping, baren soil, more sunshine, as well as location well away from forests, farm fields, pipelines, and densely populated areas. This study has determined that the area best suited for solar power plant location is in the area between the big cities of Mosul, Erbil, and Duhok, and can help provide clean and renewable energy to these urban areas. In addition, this study has helped determine other areas for future expansion in the entire region.

Supplementary Materials: The following are available online at www.mdpi.com/xxx/s1, Figure S1: title, Table S1: title, Video S1: title.

Author Contributions: Conceptualization, G.I., K.W and M.M.; methodology, G.I. ,K.W and M.M; software, G.I, K.W and M.M; validation, G.I. and K.W; formal analysis, G.I., K.W and M.M.; investigation, G.I., K.W; resources, G.I. and K.W; data curation, G.I and K.W.; writing - original draft preparation, G.I., K.W and M.M.; writingreview and editing, G.I., K.W., and M.M.; visualization, G.I, K.W. 
Funding: This research received no external funding.

Conflicts of Interest: The authors declare no conflict of interest.

\section{References:}

[1] M. Uyan, "Optimal site selection for solar power plants using multi-criteria evaluation : A case study from the Ayranci region in Karaman ," Clean Technol. Environ. Policy, 2017, doi: 10.1007/s10098-017-1405-2.

[2] A. Minelli, I. Marchesini, F. E. Taylor, P. De Rosa, L. Casagrande, and M. Cenci, "An open source GIS tool to quantify the visual impact of wind turbines and photovoltaic panels," Environ. Impact Assess. Rev., vol. 49, pp. 70-78, 2014, doi: 10.1016/j.eiar.2014.07.002.

[3] M. Uyan, "GIS-based solar farms site selection using analytic hierarchy process ( AHP ) in Karapinar region , Konya / Turkey," Renew. Sustain. Energy Rev., vol. 28, pp. 11-17, 2013, doi: 10.1016/j.rser.2013.07.042.

[4] 2009 Aydin Yonca Nazli, “No Title,” no. July, 2009.

[5] J. Xiao et al., "Research on an optimal site selection model for desert photovoltaic power plants based on analytic hierarchy process and geographic information system Research on an optimal site selection model for desert photovoltaic power plants based on analytic hiera," vol. 023132, 2013, doi: 10.1063/1.4801451.

[6] A. Asakereh, M. Omid, R. Alimardani, and F. Sarmadian, "Developing a GIS-based Fuzzy AHP Model for Selecting Solar Energy Sites in Shodirwan Region in Iran," vol. 68, pp. 37-48, 2014.

[7] M. A. Nazari, A. Aslani, and R. Ghasempour, "Analysis of Solar Farm Site Selection Based on TOPSIS Approach," vol. 9, no. 1, pp. 10-13, 2018, doi: 10.4018/IJSESD.2018010102.

[8] P. Taylor, I. Dincer, and I. Dincer, "Energy and Environmental Impacts : Present and Future Perspectives Energy and Environmental Impacts: Present and Future Perspectives," no. December 2014, pp. 37-41, 2007, doi: 10.1080/00908319808970070.

[9] D. Ginley and N. Renewable, "Solar Energy Conversion Toward," vol. 33, pp. 355-364, 2008.

[10] J. J. W. Watson and M. D. Hudson, “Landscape and Urban Planning Regional Scale wind farm and solar farm suitability assessment using GIS-assisted multi-criteria evaluation," Landsc. Urban Plan., vol. 138, pp. 20-31, 2015, doi: 10.1016/j.landurbplan.2015.02.001.

[11] G. R. F. Ibrahim, A. A. Hamid, U. M. Darwesh, and A. Rasul, "A GIS-based Boolean logicanalytical hierarchy process for solar power plant (case study: Erbil Governorate-Iraq)," Environ. Dev. Sustain., no. 0123456789, 2020, doi: 10.1007/s10668-020-00862-3.

[12] S. S. M. Al-din, M. Iranfar, and O. S. Paper, "Renewable Energy Strategies to Overcome Power Shortage in Kurdistan Region of Iraq," vol. 45, no. 2, pp. 7-21, 2017, doi: 10.5937/industrija4512770.

[13] D. H. Morad, “The Potential and Social Acceptability of Renewable Energy sources in North Iraq : Kurdistan Region."

[14] Husami, “Energy Crisis in Kurdistan And The Impact of Renewable Energy," 2007.

[15] H. Z. Al Garni and A. Awasthi, Solar PV Power Plants Site Selection: A Review, vol. 1, no. February. 2018.

[16] S. Sindhu, V. Nehra, and S. Luthra, "Investigation of feasibility study of solar farms deployment using hybrid AHP-TOPSIS analysis: Case study of India," Renew. Sustain. Energy Rev., vol. 73, no. December 2016, pp. 496-511, 2017, doi: 10.1016/j.rser.2017.01.135. 
[17] C. R. Chen, C. C. Huang, and H. J. Tsuei, "A hybrid MCDM model for improving GIS-based solar farms site selection," Int. J. Photoenergy, vol. 2014, 2014, doi: 10.1155/2014/925370.

[18] H. Z. Al Garni and A. Awasthi, "Solar PV power plant site selection using a GIS-AHP based approach with application in Saudi Arabia," Appl. Energy, vol. 206, no. October, pp. 12251240, 2017, doi: 10.1016/j.apenergy.2017.10.024.

[19] O. E. Demesouka, K. P. Anagnostopoulos, and E. Siskos, "Spatial multicriteria decision support for robust land-use suitability: The case of landfill site selection in Northeastern Greece," Eur. J. Oper. Res., vol. 272, no. 2, pp. 574-586, 2019, doi: 10.1016/j.ejor.2018.07.005.

[20] T. L. Saaty, "How to make a decision," Int. Ser. Oper. Res. Manag. Sci., vol. 175, pp. 1-21, 2012, doi: 10.1007/978-1-4614-3597-6_1.

[21] D. N. Tiwari, R. Loof, and G. N. Paudyal, "Environmental-economic decision-making in lowland irrigated agriculture using multi-criteria analysis techniques," Agric. Syst., vol. 60, no. 2, pp. 99-112, 1999, doi: 10.1016/S0308-521X(99)00021-9.

[22] and N. I. Ozge Pinar Akkas, Mustafa Yasin Erten, Ertugrul Cam, "Optimal Site Selection for a Solar Power Plant in the Central Anatolian Region of Turkey Article." .

[23] H. Z. Al Garni and A. Awasthi, "Solar PV power plant site selection using a GIS-AHP based approach with application in Saudi Arabia," Appl. Energy, vol. 206, no. October, pp. 12251240, 2017, doi: 10.1016/j.apenergy.2017.10.024.

[24] Y. Charabi and A. Gastli, "PV site suitability analysis using GIS-based spatial fuzzy multicriteria evaluation," Renew. Energy, vol. 36, no. 9, pp. 2554-2561, 2011, doi: 10.1016/j.renene.2010.10.037.

[25] G. Van De Kaa, J. Rezaei, L. Kamp, and A. De Winter, "Photovoltaic technology selection: A fuzzy MCDM approach," Renew. Sustain. Energy Rev., vol. 32, pp. 662-670, 2014, doi: 10.1016/j.rser.2014.01.044.

[26] Z. Ding, M. Zhu, Z. Wu, Y. Fu, and X. Liu, "Combining AHP-entropy approach with GIS for construction waste landfill selection-A case study of Shenzhen," Int. J. Environ. Res. Public Health, vol. 15, no. 10, 2018, doi: 10.3390/ijerph15102254.

[27] H. A. Effat, "Selection of Potential Sites for Solar Energy Farms in Ismailia Governorate, Egypt using SRTM and Multicriteria Analysis," Cloud Publ. Int. J. Adv. Remote Sens. GIS, vol. 2, no. 1, pp. 205-220, 2013, [Online]. Available: http://technical.cloudjournals.com/index.php/IJARSG/article/view/Tech-125.

[28] J. R. Janke, "Multicriteria GIS modeling of wind and solar farms in Colorado," Renew. Energy, vol. 35, no. 10, pp. 2228-2234, 2010, doi: 10.1016/j.renene.2010.03.014.

[29] G. R. F. Ibrahim, A. Rasul, A. A. Hamid, Z. F. Ali, and A. A. Dewana, "Suitable site selection for rainwater harvesting and storage case study using Dohuk governorate," Water (Switzerland), vol. 11, no. 4, 2019, doi: 10.3390/w11040864.

[30] M. Jahangiri, R. Ghaderi, A. Haghani, and O. Nematollahi, "Finding the best locations for establishment of solar-wind power stations in Middle-East using GIS: A review," Renew. Sustain. Energy Rev., vol. 66, no. December, pp. 38-52, 2016, doi: 10.1016/j.rser.2016.07.069.

[31] H. Yousefi, H. Hafeznia, and A. Yousefi-Sahzabi, "Spatial site selection for solar power plants using a gis-based boolean-fuzzy logic model: A case study of Markazi Province, Iran," Energies, vol. 11, no. 7, 2018, doi: 10.3390/en11071648.

[32] A. Hadipour, F. Vafaie, and V. Hadipour, "Land suitability evaluation for brackish water aquaculture development in coastal area of Hormozgan, Iran," Aquac. Int., vol. 23, no. 1, pp. 
329-343, 2014, doi: 10.1007/s10499-014-9818-y.

[33] M. Allaby, "Encyclopedia of weather and climate. Facts on File," Facts File Inc, vol. 15, no. 4, pp. 283-290, 2007, doi: 10.1016/0305-0483(87)90016-8.

[34] D. Ignizio, "Suitability modeling and the location of utility-scale solar power plants in the southwestern United States," 2010.

[34] Ministry of Transport \& Communication, 2019, General Directorate of Meteorology \& Seismology, sunshine duration 2010 - 2019 in Duhok province

[35] Narasimhan (2014), Area Required for Solar PV Power Plants, Online available: (http://www.suncyclopedia.com/en/area-required-for-solar-pv-power-plants) (accessed) 30/06/2020 